\title{
What works? Evidence on the role of faith in poverty reduction
}

\author{
Daniel W. O'Neilla \\ ${ }^{a}$ MD, MA(Th), Managing Editor, CJGH and Assistant Clinical Professor of Family Medicine, University of Connecticut \\ School of Medicine
}

\section{Introduction}

This unique conference was held at Yale University in New Haven, CT, USA on 20 and 21 September 2016. Matthew Frost, Chair, Joint Learning Initiative on Faith \& Local Communities (JLIFLC), and former Chief Executive of Tearfund, began the conference describing faith's role in defining narratives and providing service grounded in key social networks. Faith can no longer be thought of as a "side show" in the populations served in developing world contexts. There are gaps between the development community and the faith community - no common language, a topdown delivery system, limited accountability, and poor communication from FBOs (using "spooky" language). This calls for 1 . building evidence (including the role of religious beliefs and practices in development), 2. seeking to understand practitioners' perspectives, and 3. communicating clearly for effective change.

\section{Striving for Impact}

Dean Karlan, Professor of Economics, Yale University is founder and president of Innovations for Poverty Action (IPA). This organization brings together leading researchers and decision-makers to ensure that the evidence created leads to tangible impact on the world. He shared that FBOs are often either good at marketing but not results, or good at results without marketing. Donors respond to stories, but limited outcomes data lead to ineffective programs and policies, which leads to wasted money and enduring poverty. Data gathered might end up stuffed in inaccessible academic journals- there needs to be a bridge to action, and a move toward scalability. This requires collaboration between academics, service providers, government agencies, researchers, funders, etc. Funders are seeking better evidence for philanthropy initiatives. This requires proactively sharing solutions to 1 . design and evaluate; and 2. mobilize and support to enable better programs and policies.

David Sutherland and Lincoln Lau from International Care Ministries (ICM) described their work as a learning and business organization to fight extreme poverty. Motivated by faith and promoting hope, they shared some of their unpublished data on measuring values, health and livelihood outcomes using Protestant Christian values and theology education interventions (entitled Transform) for their service population in Philippines. ${ }^{1}$ The distinction between inputs, outputs and outcomes was discussed, with caution that correlations did not equal causation. Data gathering was to follow the CART principle: credible, actionable, responsible, and transportable. Organizations were to also follow the Goldilocks principle: not too much data and not too little. With Professor Karlan, they presented and received participant feedback on the preliminary data from an unpublished paper entitled "The impact of Protestant evangelism on religious, psychosocial and economic outcomes: a randomized experiment in the Philippines". The study design seeks to distinguish correlation from causation for a faithbased intervention. 


\section{Faith and Public Funding}

A panel moderated by Jean Duff, President of Partnership for Faith \& Development, and Coordinator of Joint Learning Initiative on Faith \& Local Communities (JLI) discussed the increase in the faith-based organization portion of the hundreds of billions of dollars of development assistance invested into developing nations. Mark Brinkmoeller, Director of the Center for FaithBased and Community Initiatives for USAID described their rules: 1. No use of funds for inherently religious activities (separate in time and location) and 2. No discrimination against beneficiaries of services. The work needs to conform to the country's goals. He noted increased cooperation between NGOs, FBOs and governments. $^{2}$ Adam Taylor, Lead for Faith-based Initiatives at World Bank Group, reminded us of their prior perceptions of FBOs as "defunct, divisive and dangerous" but that since Katherine Marshall, Berkley Center for Religion, Peace and World Affairs, Georgetown University, opened the conversation, there has been increasing receptivity to the importance of behavioral and social change at the level of world views and beliefs. Several reasons were proposed: the rise of violent extremism, the recognition of the religiosity of $80 \%$ of the world, the interest of secular peers due to the key presence of faith actors as resources, the recognition of the population influence of faith leaders, and the increase in inter-denominational cooperation. $^{3}$ The barriers to garnering support are lack of time, resources and evidence.

Azza Karam, Senior Advisor on Culture at the UN Population Fund, traced the change at the United Nations through the past 5 years, moving from "We don't do religion," to "What on earth are you doing?" There was a reappraisal of their highly secular approach after Sept 11, 2001, and there has been a recent movement from "How can we use religious leaders to do what we want?" to "What can we do to equip them?" since they provide often over $30 \%$ of the healthcare in many countries.
Ulrich Nitschke, Head of Sector Program Values, Religion and Development, Deutsche Gesellschaft für Internationale Zusammenarbeit (GIZ), described the International Partnership on Religion and Sustainable Development (PaRD $)^{4}$. This new collaborative highlights religion's positive role in change (not as the problem) and the importance of the $17^{\text {th }}$ SDG on diverse partnerships which show shared responsibility for development outcomes. The challenge is in using language for mutual understanding between faith actors and governments and other agencies. Proposed was a religious literacy course, and studying the religious landscape of the country.

\section{Achieving Scale and Impact}

Chris Udry, Henry J Heinz 11 Professor of Economics, Yale University with Dr. Karlan proposed a challenge to increase FBO credibility by presenting studies on the evidence of outcomes, not just outputs of services or "good intentions," and including control groups measuring indicators to determine effectiveness and causality. Analyzing if and why interventions work, how long they are sustainable, and making them scalable for greater impact and replicable in other settings is important. ICMs experience with pastor networks was used as an example of creating synergy toward the common good in impoverished areas. David Clingingsmith, Professor of Economics, Weatherhead School of Management, presented a randomized controlled trial which demonstrated the socially favorable effects of the hajj on Muslim participants through exposure to cultural diversity. Bruce Wydick, Professor of Economics, Program Director of International and Development Economics, University of San Francisco presented their evidence from Mexico that non-material interventions like hope, resilience, and faith can have an impact on material well-being. ${ }^{5}$ Julian Jamison, Senior Behavioral Economist of the Global INsights Initiative (GINI) at the World Bank presented research on the effectiveness and 
sustainability of cognitive behavioral therapy on post-war youth in Liberia. $^{6} \mathrm{He}$ noted the importance of constant intervention feedback loops; designing studies with fewer indices, pre-analysis plans, stronger theory; and using the terms of the recipients - including them as stakeholders.

\section{The Line in the Sand}

On the second day the conferees met at Dwight Chapel on Yale's main campus where they heard a message from Commissioner Christine McMillan, Director of Public Engagement, World Evangelical Alliance (WEA). This was followed by Ed Stetzer, Executive Director of The Billy Graham Center for Evangelism at Wheaton College, who traced the history and described the distinctive features of the trans-denominational movement of evangelicals (biblicism, crucicentrism, conversionism and activism) and their global contributions to societal transformation. He mentioned that there was an emerging body of scholarship that supported global faith-based interventions on education, religious liberty and social democracy. ${ }^{7} \quad \mathrm{He}$ referenced Lewis Rambo's work on metrics of spiritual transformation. ${ }^{8}$ As the Lausanne Covenant states, "Presence is indispensible-serving the hurting, saving the lost." While some recent studies have documented changes in multiple parameters of societal well-being through spiritual conversion and active presence, more quantitative evidence is needed.

\section{Spiritual Metrics}

David Sutherland and Lincoln Lau of ICM presented and critiqued their 50-question "Spiritual Temperature" instrument as an attempt to measure intrinsic change using multiple indicators. Mark Forshaw, Director of Global Scripture Impact, emphasized the value of showing results "moving the needle" and sharing lessons learned regarding witnessing, understanding and acting using the Engle Scale. Paul Penley, Director of Research for Excellence in Giving, emphasized the importance of entering a service population in order to design study instruments, and discussed the Santa Clara SORF spiritual metric. ${ }^{9}$ Chloé Quanrund from Tearfund, UK, shared the levels of transformation using the LIGHT Wheel as indices and its pilot projects in Uganda. ${ }^{10}$ Dan Williams from Hope International shared the Hope Quotient tool which measures material, personal, social and spiritual impact on interventions. ${ }^{11}$ Significant group discussions ensued on metrics for the conclusion of the conference.

\section{Science of Delivery}

The World Development Report 2004: Making Services Work for Poor People called for greater accountability to improve the quality of service delivery to the poor. The World Bank recognized that there had been some progress recently with converging agendas in taking local contexts seriously; building capacity of agencies (teams) to implement increasingly complex and contentious tasks at scale; and solving concrete problems and adapting solutions in real time to emergent successes and failures (as opposed to crafting elaborate plans up front and measuring success by faithful adherence to it). Closing the gap between policy aspiration and performance is a challenge that requires systematically collecting and understanding insights from practitioners in the field, "What works and what doesn't, applying it to deliver needed services to the poor." This requires 1. relentless focus on citizen outcomes, 2. multidimensional response (including FBOs), 3. evidence to achieve results (contributing to the global body of knowledge), 4. leadership for change (transformation), and 5. adaptive implementation (iterative experimentation feedback loops). ${ }^{12}$

\section{Religion, Evidence and Sustainable}

\section{Development}

There is new acknowledgement by the United Nations, funders, governments, multilaterals, the private sector, civil society and faith communities that faith plays a critical role in human develop- 
ment. ${ }^{13}$ The SDGs bring incredible new opportunity for Christian and other faith-based organizations to be included in cooperative field operations, information sharing, and resource procurement. To be of influence this will require diligent effort to design programs, initiate interventions, and share results which are based on the best evidence available, using tools that are tested and validated. The Evidence Working Group of the Joint Learning Initiative for Faith and Local Communities, of which Christian Journal for Global Health is a participant, seeks to 1 . encourage "evidence literacy" among FBOs, 2. communicate to faith communities the evidence already known about the "doability" of addressing extreme poverty, 3. share and promote the generation of evidence about the activity and impact of faith groups toward ending extreme poverty, and 4. encourage the exploration, measurement and communication of the distinctive faith assets that faith communities can bring. An on-line guide for evidence for faith groups has been initiated and is being developed. ${ }^{14}$ It is hoped that there will be increased utilization of these measurement and evaluation tools, and more valuable contribution to the effort to earnestly seek what works best for health and human flourishing.

\section{References}

1. Innovations for Poverty Action. Belief systems and poverty alleviation in the Philippines [Internet].

Available from: http://www.povertyaction.org/study/belief-systems-and-povertyalleviation-philippines

2. United States Agency for International Development [Internet]. Center for Faith-Based and Community Initiatives. Available from: https://www.usaid.gov/faith-based-and-communityinitiatives

3. The World Bank Group [Internet]. Faith and Religious Organizations. Available from: http://www.worldbank.org/en/about/partners/brief/fait h-based-organizations
4. The International Partnership on Religion and Sustainable Development (PaRD) [Internet]. Available from: http://www.partner-religiondevelopment.org/

5. Wydick B. Measuring Hope. Development Impact [Internet]. The World Bank Group. 18 April 2013. Available from: http://blogs.worldbank.org/impactevaluations/measuri ng-hope-guest-post-by-bruce-wydick

6. The World Bank Group [Internet]. Global INsights Initiative (\#WB_GINI). Behavioral and Social Change for Development. Available at: http://www.worldbank.org/en/programs/gini

7. Woodberry RD. The missionary roots of liberal democracy. Am Polit Sci Rev. 2012 May;106:244-74 https://doi.org/10.1017/S0003055412000093

8. Rambo LR, Bauman SC. Psychology of conversion and spiritual transformation. Pastoral Psychol. 2012;61(5): 879. https://doi.org/10.1007/s11089011-0364-5

9. Sherman AC, Simonton S, Adams DC, Latif U, Plante TG, Burns, SK, et al. Measuring religious faith in cancer patients: reliability and construct validity of the Santa Clara strength of religious faith questionnaire . Psycho-Oncology.2001;10:436-43. https://doi.org/10.1002/pon.523

10. The LIGHT Wheel: The learning and impact guide to holistic transformation. Available from: http://guide.jliflc.com/resources/light-wheel-learningimpact-guide-holistic-transformation/

11. HOPE Quotient monitoring and evaluation survey [Internet]. Available from: http://www.hopeinternational.org/resources/resource/ hope-quotient-survey

12. Asis MG,Woolcock M. Operationalizing the science of delivery agenda to enhance development results. World Bank Group. Oct 2015, 2-6. Available from: https://openknowledge.worldbank.org/bitstream/handl e/10986/23226/K8526.pdf?sequence $=1$

13. Sidibé M. Religion and sustainable development. Rev Faith Int Aff. Fall 2016;14(3):1-4. https://doi.org/10.1080/15570274.2016.1215848

14. Joint Learning Initiative on Faith and Local Communities [Internet]. Evidence Working Group. Guide to Excellence in Evidence for Faith Groups. Available from: http://guide.jliflc.com/resource 
Competing Interests: None declared.

Acknowledgments: Stacy Nam (JLI), Jean Duff (JLI) and Lincoln Lau (ICM) provided some revisions and references for this report. The conference was sponsored by Yale University, Innovations for Poverty Action, Joint Learning Initiative for Faith \& Local Communities, and International Care Ministries.

Correspondence: Daniel W O’Neill, Christian Journal for Global Health, dwoneill@cigh.org

Cite this article as: O'Neill DW. What works? Evidence on the role of faith in poverty reduction. Christian Journal for Global Health. Mar 2017; 4(1): 55-59.

(C) O'Neill D W This is an open-access article distributed under the terms of the Creative Commons Attribution License, which permits unrestricted use, distribution, and reproduction in any medium, provided the original author and source are properly cited. To view a copy of the license, visit https://creativecommons.org/licenses/by/4.0/

www.cjgh.org

Mar 2017. Christian Journal for Global Health, 4(1):55-59. 